\title{
Ring opening polymerization of styrene oxide initiated with potassium alkoxides and hydroxyalkoxides activated by 18-crown-6: determination of mechanism and preparation of new polyether-polyols
}

\author{
Zbigniew Grobelny ${ }^{1} \cdot$ Marek Matlengiewicz $^{1}$. \\ Justyna Jurek-Suliga $^{2} \cdot$ Sylwia Golba ${ }^{2}$. \\ Kinga Skrzeczyna ${ }^{1} \cdot$ Danuta Kwapulińska ${ }^{1}$
}

Received: 3 July 2016/Revised: 19 February 2017/Accepted: 9 March 2017/ Published online: 27 March 2017

(C) The Author(s) 2017. This article is an open access publication

\begin{abstract}
It was stated that initiation in ring opening polymerization of styrene oxide depends on the kind of potassium alkoxide activated by 18 -crown- 6 used. In the presence of potassium methoxide the oxirane ring opening occurs exclusively in the $\beta$-position and not in the $\beta$ or $\alpha$ position, i.e., contrary to the previous data. A similar result was obtained in the systems initiated with potassium $t$-butoxide, 2-methylpropoxide and 1-phenylethoxide. Unexpectedly, potassium $i$-propoxide and 1-methylpropoxide open the oxirane ring in the $\beta$ or $\alpha$ position. In all polymerizations, deprotonation of methine group in the monomer takes place under the influence of the initiator and in chain transfer reaction to the monomer. It leads to the formation of macromolecules with unsaturated starting group. However, deprotonation of methylene group in the monomer does not occur. Applying of potassium hydroxyalkoxides, i.e., monopotassium salt of dipropylene glycol or tripotassium salt of 2,2,6,6-tetrakis(hydroxymethyl)cyclohexanol it was possible to synthesize PSO-diols and PSO-pentols without unsaturation. Molar masses of polymers $\left(M_{n}=1700-4800 \mathrm{Da}\right)$ are much higher than reported in literature for other anionic systems. Dispersity of polymers is rather low $\left(M_{\mathrm{w}} / M_{n}=1.07-1.15\right)$ indicating relatively high rate of initiation and cation exchange reaction.
\end{abstract}

Keywords ROP · Oxiranes anionic polymerization - Styrene oxide $\cdot$ Potassium alkoxides · Polyether-polyols

Zbigniew Grobelny

zbigniew.grobelny@us.edu.pl

1 Institute of Chemistry, University of Silesia, 40-007 Katowice, Poland

2 Institute of Materials Science, University of Silesia, 40-007 Katowice, Poland 


\section{Introduction}

The literature data dedicated to anionic ring opening polymerization of styrene oxide (SO) are rather scarce [1-6]. The papers present the course of the process mediated with sodium [4] or potassium methoxide [2, 3]. It was reported that these compounds open the oxirane ring in the SO molecule in two positions, i.e., $\alpha$ or $\beta$, the latter even prevails $(\sim 67 \%)$ during initiation of the polymerization. However, during propagation the oxirane ring opens exclusively in the $\beta$-position. The side reactions, i.e., chain transfer to the monomer involving deprotonation of methylene and methine groups in SO molecule lead to the formation of two kinds of potassium enolates [2]. Potassium hydride was then used for SO polymerization [5]; however, the course of the process was not proposed. Molar masses of PSOs obtained with mentioned initiators were relatively low, i.e., $M_{n}=980-2900$ Da. Finally, cyclic oligo(potassium glycidoxide)s with three or six alkoxide groups activated by coronand 18-crown-6 (18C6) were also applied as macroinitiators for the ROP of SO [6]. Star-shaped polyether-polyols with $M_{n}=8000 \mathrm{Da}$ were prepared in this way.

It is well known [7] that crown ethers can form stable complexes with metal cations when the size of the crown ether cavity matches that of the cation (Scheme 1). This complexation leads to a considerable increase in the degree of ionpair separation. In the anionic polymerization of propylene oxide and other oxiranes complexation of the cation causes a marked activating effect. As a result one observes positive impact on reaction rate, lower unsaturation level in the polymer [8] and higher yield of the final product [9].

Styrene oxide was polymerized recently with the use of different tin catalysts [10], rare earth coordination catalysts [11] or with acid-exchanged montmorillonite clay [12]. Poly(styrene oxide) can be used as drug carriers [13]. Polystyrene oxidepolyethylene oxide (PSO-PEO) block copolymers were used in the design of efficient nanocarriers for cancer chemotherapy [14, 15]. Based on PSO-PEO triblock copolymers were synthesized. It produced the drug-loaded micelles and their drug release profiles were analyzed for the anticancer drug, doxorubicin (DOXO) [15] PSO was also used for production of polystyrene carbonate [16].

The aim of this work was reinvestigation of SO ROP course in the presence of potassium alkoxides as well as preparation and characterization of new PSOpolyols. Several initiators activated by $18 \mathrm{C} 6$ were chosen for the study, i.e., potassium methoxide, potassium $i$-propoxide, potassium $t$-butoxide, potassium 1-methylpropoxide, potassium 2-methylpropoxide, potassium 1-phenylethoxide, monopotassium salt of dipropylene glycol as well as tripotassium salt of 2,2,6,6tetrakis(hydroxymethyl)cyclohexanol. The polymers obtained by use of hydroxyalkoxides are especially interesting, because they possess several $\mathrm{OH}$ terminal groups after hydrolysis and can be used as potential macromonomers for synthesis

$$
\mathrm{ROH}+\mathrm{KH} / 18 \mathrm{C} 6 \stackrel{\mathrm{THF}, \mathrm{RT}}{\longrightarrow} \mathrm{RO}^{-} \mathrm{K}^{+}+\mathrm{H}_{2} \uparrow
$$

Scheme 1 Synthesis of potassium alkoxide in the presence of 18-crown-6 complexing agent 
of new polyurethanes, used in the production of mattresses and also in the furniture industry, automotive industry, building industry and for special applications, for example, medicine. Preparation of the initiators as well as polymerizations were carried out in mild conditions, i.e., in tetrahydrofuran solution at room temperature.

\section{Experiment}

\section{Materials}

Styrene oxide (Aldrich) was dried over $\mathrm{CaH}_{2}$ and then distilled at $467 \mathrm{~K}\left(194{ }^{\circ} \mathrm{C}\right)$. Anhydrous tetrahydrofuran (THF) (Acros Organics) was kept over $\mathrm{CaH}_{2}$ and distilled at $339 \mathrm{~K}\left(66{ }^{\circ} \mathrm{C}\right)$. Potassium hydride $(\mathrm{KH})$ (Aldrich) was purified according to the procedure described by Brown [17]. A $35 \mathrm{wt} \%$ dispersion of $\mathrm{KH}$ in mineral oil (Aldrich) was mixed with $n$-pentane in a dry argon atmosphere and then decanted. It was repeated three times followed by a threefold washing with dry THF. Finally, THF was evaporated in vacuum. The KH present was determined by a standard gas law calculation of the hydrogen liberated after treatment with 2-butanol $\left(1.0 \mathrm{H}_{2}=1.0 \mathrm{KH}\right)$. The resulting solution was titrated to a phenolphthalein end point. Very little excess $(<1 \%)$ of total base over hydride base (from gas evolution) indicated small hydrolysis of the original $\mathrm{KH}$ sample. Coronand 18C6 (1,4,7,10,13,16-hexaoxacyclooctadecane) (Merck), methanol, $i$-propanol, 1-phenylethanol, 1-methylpropanol, 2-methylpropanol, dipropylene glycol, 2,2,6,6-tetrakis(hydroxymethyl)cyclohexanol and potassium $t$-butoxide in THF solution $\left(1.0 \mathrm{~mol} / \mathrm{dm}^{3}\right)$ (all from Aldrich) were used as received for synthesis without further purification.

\section{Preparation of initiators and styrene oxide polymerization}

All syntheses were performed at $20{ }^{\circ} \mathrm{C}$ in a $50 \mathrm{~cm}^{3}$ reactor equipped with a magnetic stirrer and a Teflon valve enabling substrate delivery and sampling under argon atmosphere. Monopotassium salts were obtained in the reaction of potassium hydride with an appropriate amount of alcohol or dipropylene glycol (DPG) dissolved in THF containing $18 \mathrm{C} 6$ at $20^{\circ} \mathrm{C}$. The initial concentrations of the monomer were 2.0 or $5.0 \mathrm{~mol} / \mathrm{dm}^{3}$ and the initial concentration of the initiator was $0.1 \mathrm{~mol} / \mathrm{dm}^{3}$. For example, potassium hydride $(0.08 \mathrm{~g}, 2.0 \mathrm{mmol})$ and $\mathrm{THF}$ $\left(15.0 \mathrm{~cm}^{3}\right)$ were introduced into the reactor and then $18 \mathrm{C} 6(0.53 \mathrm{~g}, 2.0 \mathrm{mmol})$ and methanol $(0.064 \mathrm{~g}, 2.0 \mathrm{mmol})$ were added by use of syringe. The mixture was stirred for $1.5 \mathrm{~h}$ until all hydrogen $\left(44.7 \mathrm{~cm}^{3}\right)$ was evolved. It resulted in a suspension of pure anhydrous potassium methoxide activated ligand in the ether solution. That system was used as the initiator, when styrene oxide $\left(4.6 \mathrm{~cm}^{3}, 3.7 \mathrm{~g}\right.$, $40 \mathrm{mmol}$ ) was introduced into the reactor. The reaction mixture was then stirred for several days. After almost complete conversion of the monomer the reaction mixture was neutralized with $\mathrm{HCl} / \mathrm{H}_{2} \mathrm{O}$ system $\left(0.1 \mathrm{~mol} / \mathrm{dm}^{3}, 70 \mathrm{~cm}^{3}\right)$ and transferred to the separator containing chloroform $\left(70 \mathrm{~cm}^{3}\right)$. After shaking, two layers were formed, i.e., an inferior polyether layer and a superior layer containing 
water and the potassium salt. These layers were separated and the superior layer was removed. After three washes with fresh water, polyether was obtained by chloroform and water distillation in vacuum at $100{ }^{\circ} \mathrm{C}$.

In another experiment, tripotassium salt of 2,2,6,6-tetrakis(hydroxymethyl)cyclohexanol (TKHMCH) activated by $18 \mathrm{C} 6$ was prepared in a similar way. The initial concentration of the monomer was 2.0 or $4.0 \mathrm{~mol} / \mathrm{dm}^{3}$ and the initial concentration of the initiator was $0.02 \mathrm{~mol} / \mathrm{dm}^{3}$. Potassium hydride $(0.048 \mathrm{~g}, 1.2 \mathrm{mmol})$, THF $\left(5.0 \mathrm{~cm}^{3}\right)$ and $18 \mathrm{C} 6(0.32 \mathrm{~g}, 1.2 \mathrm{mmol})$ were introduced into the reactor. Then TKHMCH (0.088 g, $0.4 \mathrm{mmol})$ was dissolved in boiling THF $\left(10.0 \mathrm{~cm}^{3}\right)$ and the solution obtained was dropped into the system at $20^{\circ} \mathrm{C}$. After mixing for $1.5 \mathrm{~h}$, hydrogen $\left(26.8 \mathrm{~cm}^{3}\right)$ was evolved. Finally, styrene oxide $\left(4.6 \mathrm{~cm}^{3}, 3.7 \mathrm{~g}, 40 \mathrm{mmol}\right)$ was added and the reaction mixture was stirred for several days until complete monomer conversion. The separation of polymer obtained was performed as described previously. At the stage of shaking with the $\mathrm{HCl} / \mathrm{H}_{2} \mathrm{O}$ system, some additional interlayer was formed that may contain polyether with fully converted $\mathrm{OH}$ groups or in equilibrium with the polyether with some rest OK groups. The presence of monomer during polymerization was monitored by chromatographic method. After ending of the polymerization, all reaction mixtures were homogeneous.

\section{Measurements}

$100 \mathrm{MHz}{ }^{13} \mathrm{C}$ nuclear magnetic resonance (NMR) spectra were recorded in $\mathrm{CDCl}_{3}$ at $25{ }^{\circ} \mathrm{C}$ on a BrukerAvance 400 pulsed spectrometer equipped with $5 \mathrm{~mm}$ broadband probe and applying Waltz16 decoupling sequence. Chemical shifts were referenced to tetramethylsilane serving as an internal standard. To obtain a good spectrum of the polymer main chain exhibiting its microstructural details, about 3000 scans were satisfactory, but in order to observe the signals of the polymer chain ends more than 10,000 scans were necessary. Molar masses and dispersities of polymers were obtained by means of size exclusion chromatography (SEC) on a Shimadzu Prominence UFLC instrument at $40{ }^{\circ} \mathrm{C}$ on a Shodex $300 \mathrm{~mm} \times 8 \mathrm{~mm}$ OHpac column using tetrahydrofuran as a solvent. Polystyrenes were used as calibration standards. Matrix-assisted laser desorption/ionization-time of flight (MALDI-TOF) spectra were recorded on a Shimadzu AXIMA Performance instrument. Dithranol was used as a matrix. Spectrophotometer measurements were performed on the FTIR ATR device (Shimadzu IR Prestige) equipped with diamond ATR crystal purified prior to measurement with isopropanol. Data were analyzed using LabSolutions program.

\section{Results and discussion}

In the present work polymerization of styrene oxide was carried out in the presence of ether 18-crown-6. This macrocyclic ligand is frequently used for activation of alkoxide anions due to strong complexation of metal cation. It results in the formation of crown-separated ion pairs and allows maintaining a high rate of polymerization of propylene oxide at low temperature [5]. 
${ }^{13} \mathrm{C}$ NMR was used as the main technique for analysis of the polymers obtained in order to determine the course of ROP. In some cases MALDI-TOF was also applied as a supporting method. Due to the relatively short polymer chains of the samples, ${ }^{13} \mathrm{C}$ NMR could be eventually applied to estimate the molar masses; however, in some cases the signals of the end groups were very small and close to the noise level or overlapped with the strong signals of the backbone carbons, and due to possible side reactions, simple integration of these signals may introduce significant error; therefore, the molar masses and dispersities of the polymers were estimated by SEC chromatography.

\section{Determination of the mechanism of SO polymerization in the presence of simple potassium alkoxides activated by $18 \mathrm{C6}$}

Data characterizing the polymers obtained are presented in Table 1. They involve molar masses, dispersities and unsaturation of PSOs.

Figure 1 shows the characteristic signals of ${ }^{13} \mathrm{C}$ NMR spectra for the starting groups of the polymers obtained in the presence of three initiators, i.e., potassium methoxide (Fig. 1a-I1), potassium $i$-propoxide (Fig. 1b-I2) and potassium $t$ butoxide (Fig. 1c-I3).

Analysis of ${ }^{13} \mathrm{C}$ NMR spectrum indicated that initiation of SO polymerization with potassium methoxide (I1) (Fig. 1a) occurs by a different way than it was reported in the literature [2-4]. Methyl signal of the starting group $\mathrm{CH}_{3} \mathrm{OCH}_{2-}$ $\mathrm{CH}(\mathrm{Ph}) \mathrm{O}-(59.21 \mathrm{ppm})$ is observed in the spectrum after quenching with $\mathrm{HCl} / \mathrm{H}_{2} \mathrm{O}$ resulting from $\mathrm{SO}$ ring opening in the $\beta$-position under influence of the initiator. A hypothetical second signal of starting group $\mathrm{CH}_{3} \mathrm{OCH}(\mathrm{Ph}) \mathrm{CH}_{2} \mathrm{O}-$ (at about $57.0 \mathrm{ppm}$ ) is absent in the spectrum which eliminates the possibility of monomer ring opening also in $\alpha$-position. However, such a signal was detected in the spectrum of PSO quenched with $\mathrm{CH}_{3} \mathrm{I}$ as the signal of the end group. The results obtained clearly indicated that in the initiation as well as propagation step the oxirane ring opened exclusively in the $\beta$-position.

A similar effect was observed in the polymerization initiated with potassium $t$ butoxide (I3) (Fig. 1c). However, in the presence of potassium $i$-propoxide (I2) the oxirane ring opens in the $\beta$ - or $\alpha$-position $(\sim 1 / 1)$. In ${ }^{13} \mathrm{C}$ NMR spectrum of the polymer, two signals of $\mathrm{CH}_{3}$ group are present (Fig. 1b). We proposed that these two signals were derived from two kinds of starting $i$-propoxy groups, i.e. $\left(\mathrm{CH}_{3}\right)_{2-}$ $\mathrm{CHOCH}_{2} \mathrm{CH}(\mathrm{Ph}) \mathrm{O}-(22.21 \mathrm{ppm})$ and $\left(\mathrm{CH}_{3}\right)_{2} \mathrm{CHOCH}(\mathrm{Ph}) \mathrm{CH}_{2} \mathrm{O}-(22.05 \mathrm{ppm})$. Further splitting only of the latter one, may be due to the closer vicinity of its methyl groups to the asymmetric carbon $-\mathrm{CHPh}-$. It was interesting that replacement of one $\mathrm{CH}_{3}-$ group in potassium $i$-propoxide by the greater $\mathrm{CH}_{3} \mathrm{CH}_{2}-$ group partly conserves the observed phenomenon. In the presence of potassium 1-methylpropoxide (I5) oxirane ring also opens in the $\beta$ - or $\alpha$-position $(\sim 1 / 0.2)$. Figure 2 shows the aliphatic part of the ${ }^{13} \mathrm{C}$ NMR spectrum of PSO obtained with the mentioned initiator. According to notation in Fig. 2, the predominating signals of the starting group formed during $\beta$-opening (carbons 1 , 2 and 3) may be found at 9.73, 29.07, and $19.14 \mathrm{ppm}$, respectively, while those from $\alpha$-opening (carbons 4, 5 and 6) at 9.88, 32.04, and 22.10, respectively. Splitting of 


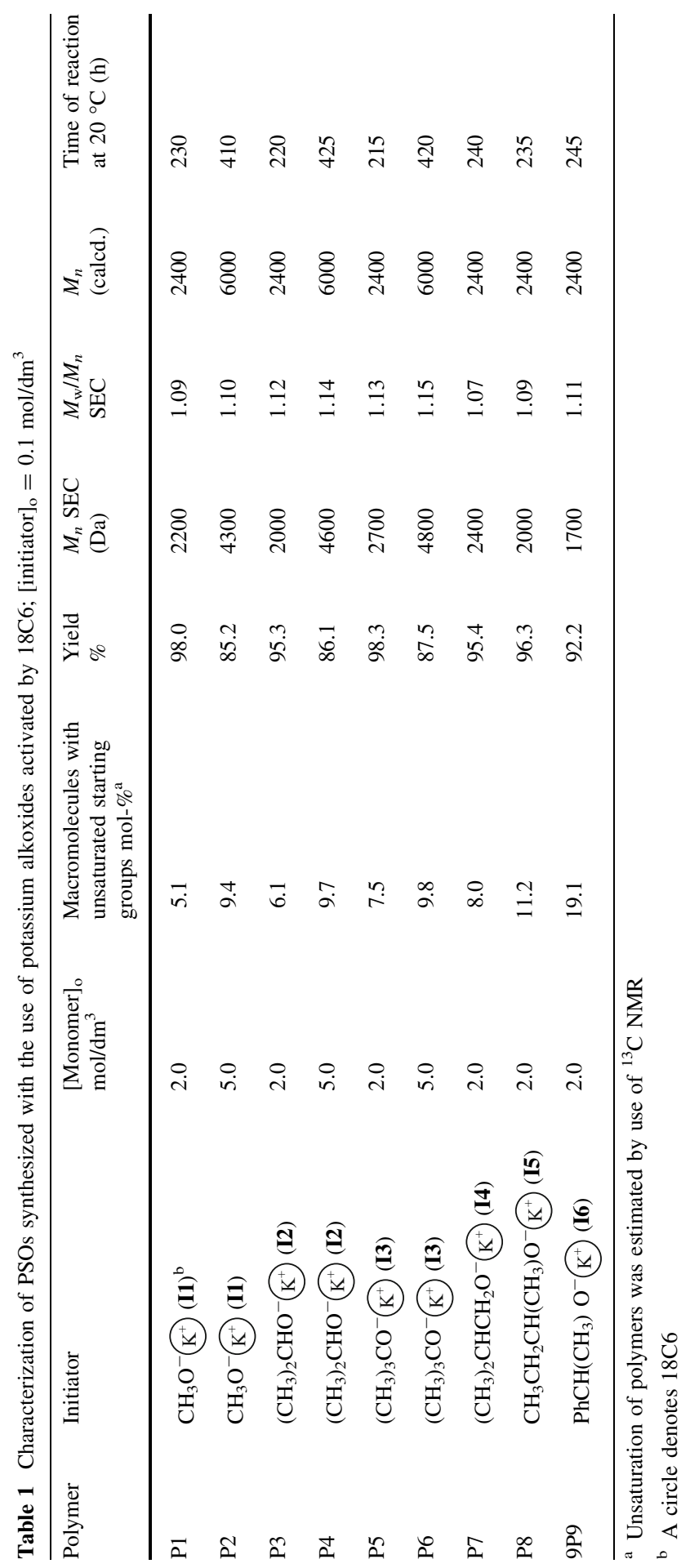


$\mathrm{H}_{3} \mathrm{C}-\mathrm{O}-\mathrm{CH}_{2}-\mathrm{HC}-\mathrm{O}-$

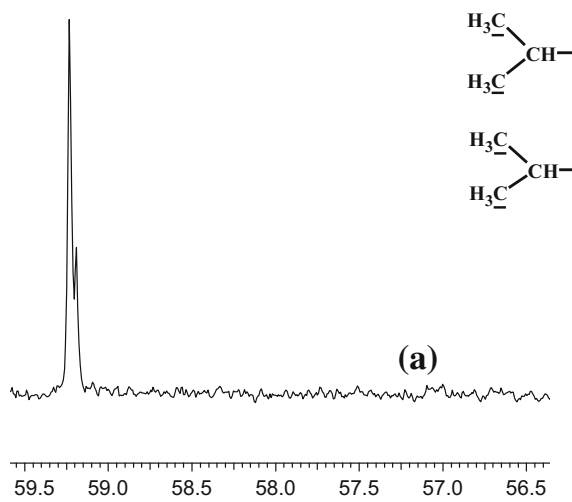<smiles>CO[C@H](COC(C)(C)C)c1ccccc1</smiles>

(b)
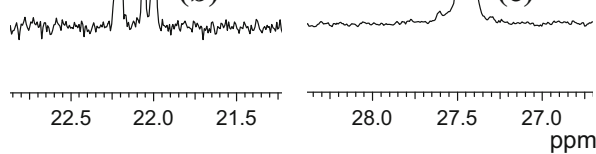

Fig. 1 Signals of methyl carbons present in starting groups of PSOs synthesized with (a) $\mathrm{CH}_{3} \mathrm{O}^{-} \mathrm{K}^{+}$ (I1), (b) $\left(\mathrm{CH}_{3}\right)_{2} \mathrm{CHO}^{-} \mathrm{K}^{+}(\mathbf{I}),(\mathbf{c})\left(\mathrm{CH}_{3}\right)_{3} \mathrm{CO}^{-} \mathrm{K}^{+}(\mathbf{I 3})$
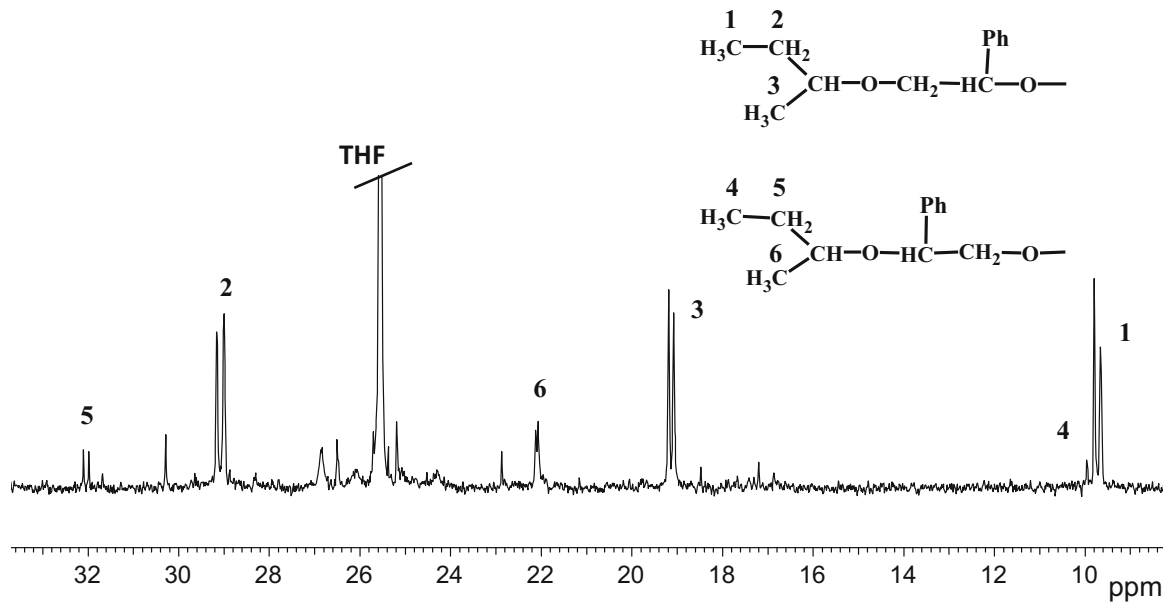

Fig. 2 Signals of methyl and methylene carbons present in starting groups of PSO (P8) synthesized with $\mathrm{CH}_{3} \mathrm{CH}_{2} \mathrm{CH}\left(\mathrm{CH}_{3}\right) \mathrm{O}^{-} \mathrm{K}^{+}(\mathbf{I 5})$

all the mentioned signals into two lines may be due to the presence of asymmetric methine carbon in these groups as it was already observed in our earlier work on PPO [18]. The presence of additional minor signals in this region may indicate some side reactions; however, the source of these reactions is yet unknown.

However, replacement of one $\mathrm{CH}_{3}-$ group by $\mathrm{Ph}-$ one in potassium 1-phenylethoxide (I6) or introduction of $-\mathrm{CH}_{2}-$ group between $i$-Pr- and $-\mathrm{O}^{-} \mathrm{K}^{-}$ groups in potassium 2-methylpropoxide (I4) results in the ring opening during the 

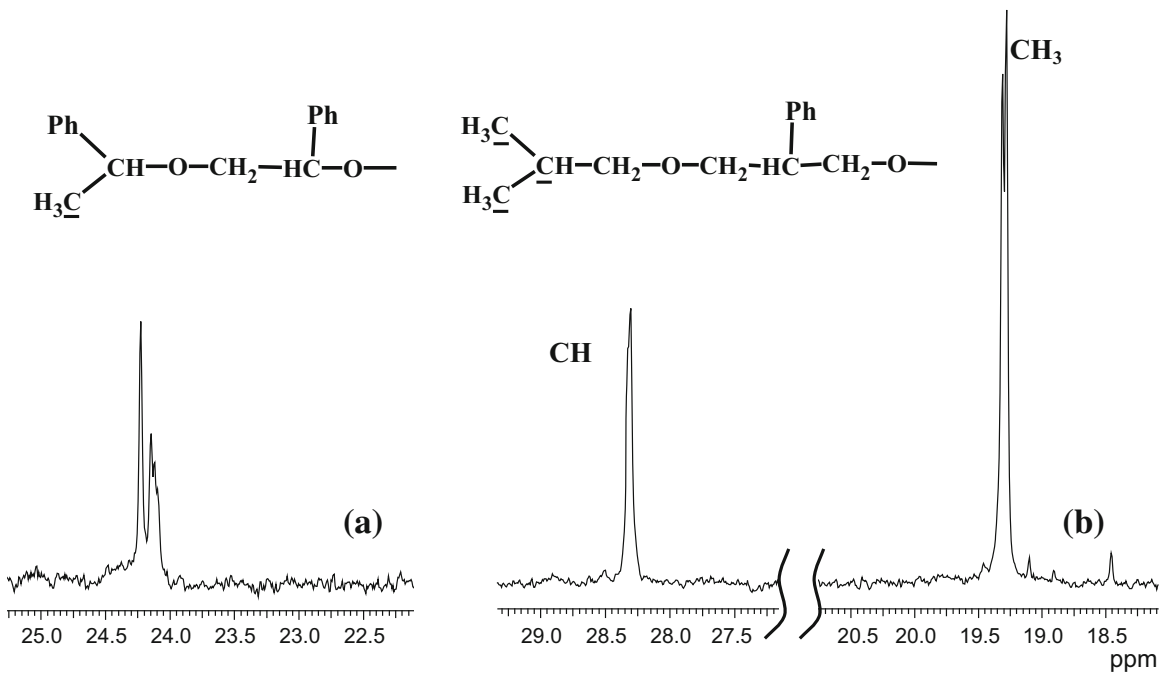

Fig. 3 Signals of methyl carbons present in starting groups of PSOs synthesized with $\mathrm{PhCH}\left(\mathrm{CH}_{3}\right) \mathrm{O}^{-}$ $\mathrm{K}^{+}$ (I6)-spectrum (a-for P9) and $\left(\mathrm{CH}_{3}\right)_{2} \mathrm{CHCH}_{2} \mathrm{O}^{-} \mathrm{K}^{+}(\mathbf{I 4})$-spectrum (b-for P7)

initiation exclusively in the $\beta$-position (Fig. 3). Opening in the $\alpha$-position should lead to creation of a second signal for methyl group, shifted of about $0.4 \mathrm{ppm}$ but no such signal is observed (Fig. 3a).

The results obtained indicate, that the structure of initiator used influences the direction of oxirane ring-opening in anionic polymerization of styrene oxide (Scheme 2).

In the unsaturated region of ${ }^{13} \mathrm{C}$ NMR spectra of the obtained polymers two weak signals were observed at 133.02 and $159.66 \mathrm{ppm}$ (Fig. 4). It was proposed that these signals derived from carbons of unsaturated starting groups $\mathrm{CH}_{2}=\mathrm{C}(\mathrm{Ph})-\mathrm{O}-$ (quaternary carbon at $159.66 \mathrm{ppm}$ ). Their formation by chain transfer to the monomer was presented on Scheme 3.

This reaction proceeded by deprotonation of monomer methine group with growing chain end resulting from the presence of acidic $\mathrm{H}$-atom in $\mathrm{PhCH}$ group. However, the lack of the signals in ${ }^{13} \mathrm{C}$ NMR spectrum at about 108 and $146 \mathrm{ppm}$ of vinyl carbons in hypothetical starting group,

$\mathrm{Ph}-\mathrm{CH}=\mathrm{CH}-\mathrm{O}-$ indicated, that reported in the literature deprotonation of methylene group in SO molecule did not occur. Signal of carbonyl group was also absent in the spectrum. Unsaturation of polymers increases with initial concentration of the monomer (Table 1). Chain transfer to the monomer is responsible for this phenomenon (Scheme 2). However, unsaturation of polymers depends also on the kind of initiator used. The lowest unsaturation has PSO obtained with $\mathrm{CH}_{3} \mathrm{O}^{-} \mathrm{K}(\sim 5 \%)$, the highest one $(\sim 19 \%)$ exhibits polymer prepared with $\mathrm{PhCH}\left(\mathrm{CH}_{3}\right) \mathrm{O}^{-} \mathrm{K}^{-}$. It means, that the second source of unsaturation is deprotonation of the monomer by initiator.

Molar masses of synthesized polymers $\left(M_{n}=1700-4800 \mathrm{Da}\right)$ are higher than those reported in the literature for polymers prepared in toluene solution at $80{ }^{\circ} \mathrm{C}$ $\left(M_{n}=980-1200 \mathrm{Da}\right)$ or in bulk at $100{ }^{\circ} \mathrm{C}\left(M_{n}=2400-2900 \mathrm{Da}\right)$. Analysis of the 


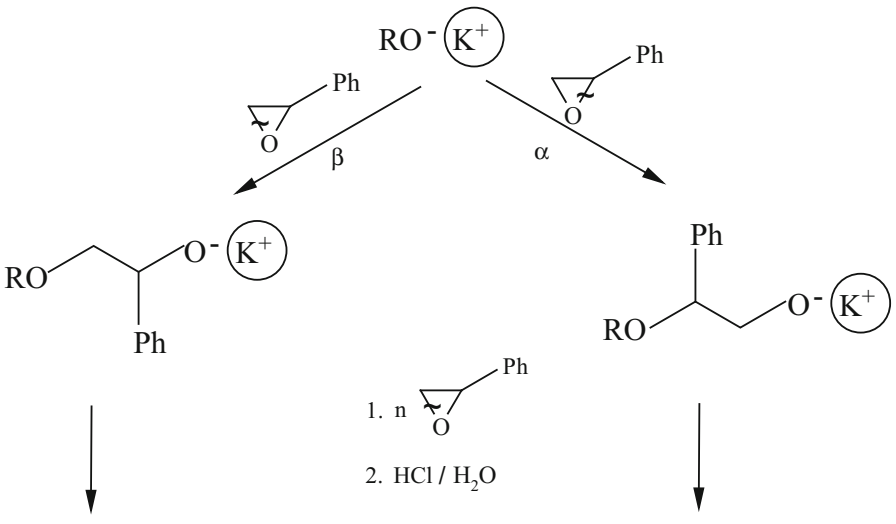<smiles>[R20]CC(OCC(OCCO)c1ccccc1)c1ccccc1</smiles><smiles>[R20]C(COCC(OCCO)c1ccccc1)c1ccccc1</smiles>

$\mathrm{R}(\beta): \mathrm{CH}_{3} \mathrm{O},\left(\mathrm{CH}_{3}\right)_{3} \mathrm{CO}, \mathrm{PhCH}\left(\mathrm{CH}_{3}\right) \mathrm{O},\left(\mathrm{CH}_{3}\right)_{2} \mathrm{CHCH}_{2} \mathrm{O}$

$\mathrm{R}(\beta$ and $\alpha):\left(\mathrm{CH}_{3}\right)_{2} \mathrm{CHO}, \mathrm{CH}_{3} \mathrm{CH}_{2} \mathrm{CH}\left(\mathrm{CH}_{3}\right) \mathrm{O}$

Scheme 2 ROP of SO initiated with potassium alkoxides activated by $18 \mathrm{C} 6$

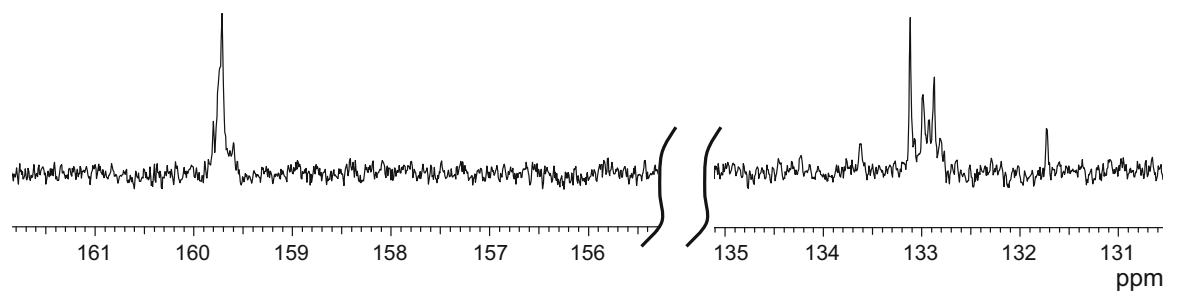

Fig. 4 Signals of unsaturated starting group present in PSOs (I3) prepared with potassium alkoxides activated by $18 \mathrm{C} 6$

polymers by MALDI-TOF spectroscopy confirmed the formation of macromolecules with unsaturated starting groups. Figure 5 shows for example MALDITOF spectrum of PSO obtained with $\left(\mathrm{CH}_{3}\right)_{2} \mathrm{CHO}^{-} \mathrm{K}^{-}$.

Dispersity of polymers is relatively low, i.e., $M_{\mathrm{w}} / M_{n}=1.07-1.15$, indicating high rate of cation exchange reaction. MALDI-TOF analysis of polymer 3 further confirmed its chemical structure (Fig. 5).

Three main series of signals were observed in the spectrum. The first series at $\mathrm{m} / \mathrm{z}$ 1056.3-2133.9 represents macromolecules possessing isopropyloxy starting group and $\mathrm{OH}$ end group. For example, signals at $\mathrm{m} / \mathrm{z} 1178.1,1538.7$ and 1897.6 represent macromolecules containing 9,12 and 15 mers of styrene oxide $\left(M_{n}\right.$ $($ calcd. $)=1180.6,1541.0$ and 1901.5 respectively $)$. They form adducts with $\mathrm{K}^{+}$ 
Scheme 3 Chain transfer to the monomer in SO polymerization initiated with potassium alkoxides activated by $18 \mathrm{C} 6$

$$
\ldots-\mathrm{O}^{-} \mathrm{K}^{+}+\underset{\mathrm{OH}}{+}
$$<smiles>C=C(Oc1cccc(CC)c1)C(=O)c1ccccc1</smiles><smiles>C=C(OCC(OCCO)c1ccccc1)c1ccccc1</smiles>

ions. The second series at 1040.3-2117.9 represents macromolecules with the same structure, but forming adducts with $\mathrm{Na}^{+}$ions. However, the third series of peaks at $m / z$ 1117.7-1839.0 represents macromolecules possessing unsaturated starting group and $\mathrm{OH}$ end group. They form adducts with $\mathrm{K}^{+}$ions. For example, signals at $m / z$ 1239.4, 1479.8 and 1839.0 represent macromolecules containing 9, 11 and 14 mers of styrene oxide $\left(M_{n}\right.$ (calcd. $)=1240.6,1480.9$ and 1841.3 respectively $)$.

\section{Synthesis of PSO-polyols by polymerization of SO initiated with potassium hydroxyalkoxides activated by $18 \mathrm{C} 6$}

Data concerning the PSOs with several hydroxyl end groups were presented in Table 2. They were synthesized in processes initiated with monopotassium salt of dipropylene glycol (K-DPG) (I7) or tripotassium salt of 2,2,6,6-tetrakis (hydroxymethyl) cyclohexanol (3K-TKHMCH) (I8) (Scheme 4).

Figure 6 shows ${ }^{13} \mathrm{C}$ NMR spectrum of macrodiol obtained at low initial concentration of monomer, i.e., $[\mathrm{SO}]_{\mathrm{o}}=2.0 \mathrm{~mol} / \mathrm{dm}^{3}$. 


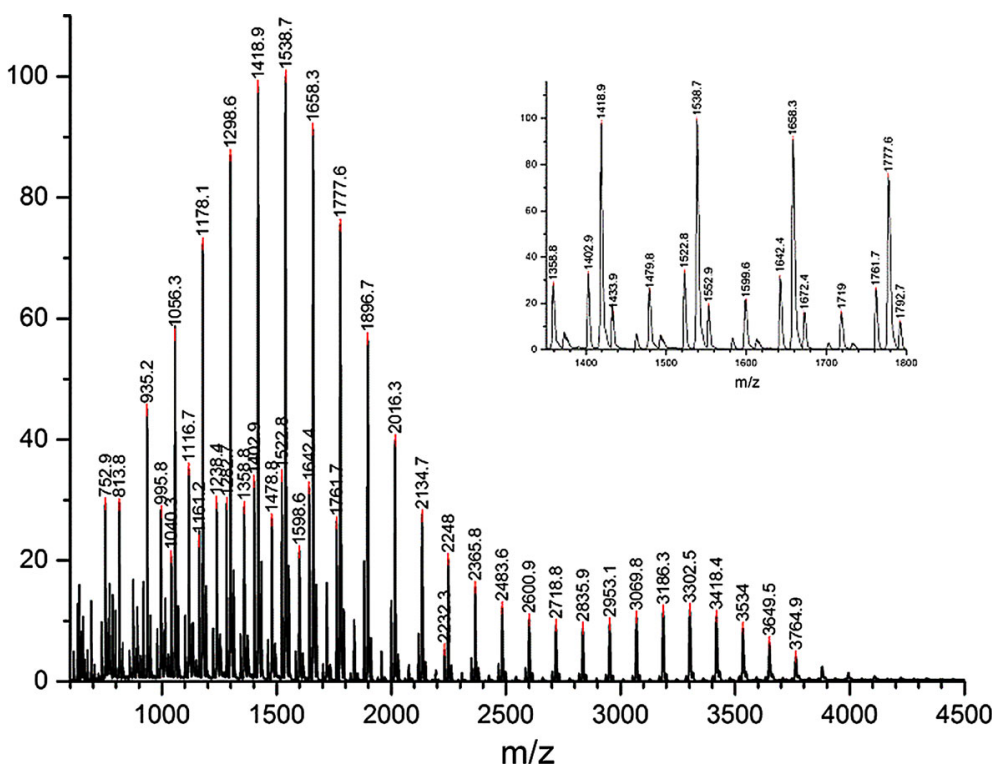

Fig. 5 MALDI-TOF spectrum of PSO-diol (P3) synthesized with the use of $\left(\mathrm{CH}_{3}\right)_{2} \mathrm{CHO}^{-} \mathrm{K}^{-}$(I2) and quenched with $\mathrm{HCl} / \mathrm{H}_{2} \mathrm{O}$

Table 2 Characterization of macrodiols and macropentols synthesized by anionic polymerization of SO initiated with potassium hydroxyalkoxides; $[\mathrm{K}-\mathrm{DPG}]_{\mathrm{o}}=0.1 \mathrm{~mol} / \mathrm{dm}^{3} ;[3 \mathrm{~K}-\mathrm{TKHMCH}]_{\mathrm{o}}=0.02 \mathrm{~mol} / \mathrm{dm}^{3}$

\begin{tabular}{|c|c|c|c|c|c|c|c|c|}
\hline Polymer & Initiator & $\underset{\left.\mathrm{mol}^{2} / \mathrm{dm}^{3}\right]_{\mathrm{o}}}{\text { Monomer }}$ & $\begin{array}{c}\text { Yield } \\
\%\end{array}$ & & $\begin{array}{c}\mathrm{M}_{\mathrm{n}} \\
\mathrm{SEC} \\
{[\mathrm{Da}]}\end{array}$ & $\begin{array}{c}\mathrm{M}_{\mathrm{w}} / \mathrm{M}_{\mathrm{n}} \\
\mathrm{SEC}\end{array}$ & $\begin{array}{c}\mathrm{M}_{\mathrm{n}} \\
\text { (Calcd.) }\end{array}$ & $\begin{array}{c}\text { Time of } \\
\text { reaction at } \\
20^{\circ} \mathrm{C} \\
{[\mathrm{h}]}\end{array}$ \\
\hline $\mathrm{P} 10$ & K-DPG (I7) & 2.0 & 98.8 & & 2600 & 1.12 & 2400 & 450 \\
\hline P11 & K-DPG (I7) & 5.0 & 68.1 & & 4100 & 1.15 & 6000 & 520 \\
\hline P12 & 3K-TKHMCH (I8) & 2.0 & $\begin{array}{l}88.1 \\
10.3\end{array}$ & 2 fractions & $\begin{array}{l}3500 \\
2700\end{array}$ & $\begin{array}{l}1.42 \\
1.17\end{array}$ & 12000 & 600 \\
\hline P13 & 3K-TKHМCH (I8) & 4.0 & $\begin{array}{l}22.0 \\
42.7 \\
20.9\end{array}$ & 3 fractions & $\begin{array}{l}5500 \\
3000 \\
1200\end{array}$ & $\begin{array}{l}1.03 \\
1.05 \\
1.10\end{array}$ & 24000 & 720 \\
\hline
\end{tabular}

$\mathrm{HO} \mathrm{C}_{3} \mathrm{H}_{6} \mathrm{O} \mathrm{C}_{3} \mathrm{H}_{6} \mathrm{O}^{-} \mathrm{K}^{+}$

K - DPG (I7)

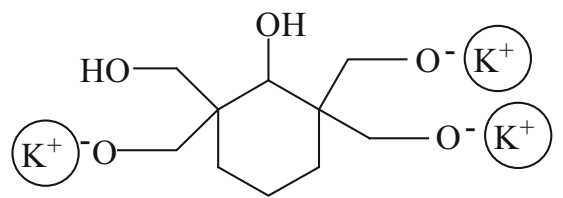

$3 \mathrm{~K}-\mathrm{TKHMCH}$

(I8)

Scheme 4 Potassium hydroxyalkoxides used for preparation of PSO-polyols-K-DPG (I7) and 3KTKHMCH (I8) 


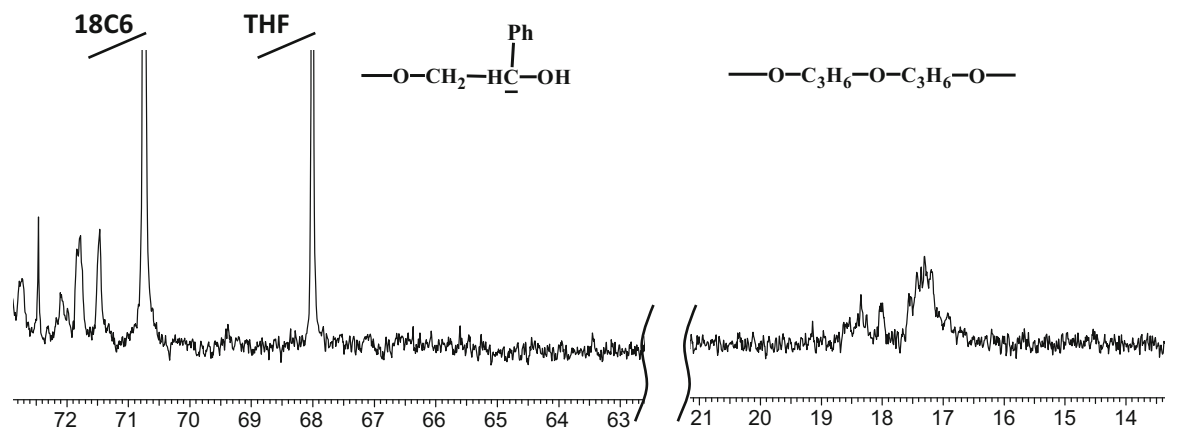

Fig. $6{ }^{13} \mathrm{C}$ NMR spectrum of PSO-diol (P10) derived in ROP in the presence of K-DPG (I7) and quenched with $\mathrm{HCl} / \mathrm{H}_{2} \mathrm{O}$
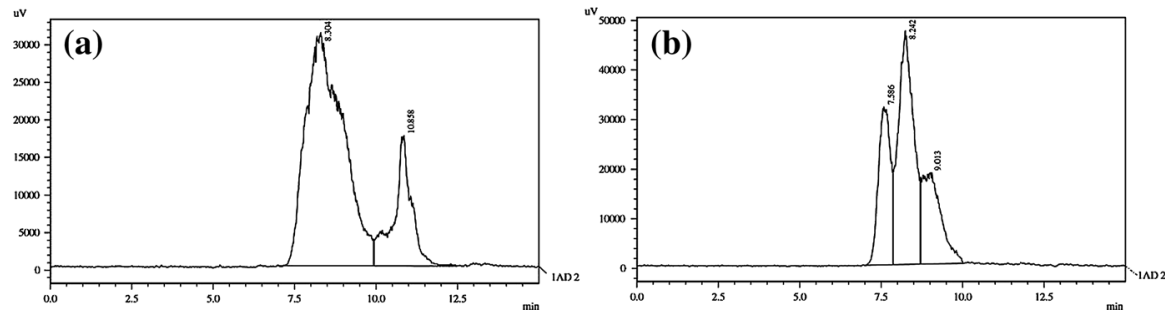

Fig. 7 SEC chromatogram for polymer 12 (p12) obtained with initiator I8 and polymer 13 (p13) obtained with initiator $\mathbf{I 8}$

Signals at $17.1 \mathrm{ppm}$ derived from $\mathrm{CH}_{3}$ - groups of initiator. Signals of terminal groups $\mathrm{CH}_{2} \mathrm{CH}(\mathrm{Ph}) \mathrm{OH}$ which should arrive at about 73.8 ppm cannot be precisely identified since they fall in the region of the strong main chain signal, nevertheless, a sharp signal at $73.65 \mathrm{ppm}$ could be observed in this broad band. However, signals of starting groups derived from initiator, i.e., $-\mathrm{CH}_{2} \mathrm{CH}\left(\mathrm{CH}_{3}\right) \mathrm{OH}$ which should arrive at about $66.6 \mathrm{ppm}$ as well as signals of unsaturated starting groups were not observed in the spectrum.

Figure 7 presents SEC chromatogram recorded for polymer 12 (p12) obtained with initiator $\mathbf{I 8}$ and polymer 13 (p13) obtained with initiator I8.

For polymer 12 (p12) two main fractions are present as the product of the synthesis, while for polymer 13 (p13) three fraction can be separated.

FTIR spectra were recorded for polymers P10-P13 using ATR technique (Fig. 8). For synthesised polymers the main chain is composed of alkane-like fragments $\left(-\mathrm{CH}_{2}-\right)$. Hence stretching of $-\mathrm{C}-\mathrm{H}$ reflects bands at $3000-2850 \mathrm{~cm}^{-1}$ is visible with bending/scissoring vibration of $\mathrm{C}-\mathrm{H}$ in the range $1470-1450 \mathrm{~cm}^{-1}$ and rocking ones of $\mathrm{C}-\mathrm{H}$ at $1370-1350 \mathrm{~cm}^{-1}$ and $750-720 \mathrm{~cm}^{-1}$. Presence of aromatic phenyl ring is manifested with $\mathrm{C}=\mathrm{C}-\mathrm{H}$ stretching bands located in the range above $3000 \mathrm{~cm}^{-1} \quad\left(3100-3000 \mathrm{~cm}^{-1}\right)$. The absorption within the range of $1600-1585 \mathrm{~cm}^{-1}$ and $1500-1400 \mathrm{~cm}^{-1}$ is caused by stretching bands of $-\mathrm{C}=\mathrm{C}-$ in aromatic rings. Low intensity bands at $3492 \mathrm{~cm}^{-1}$ represent stretching vibration 


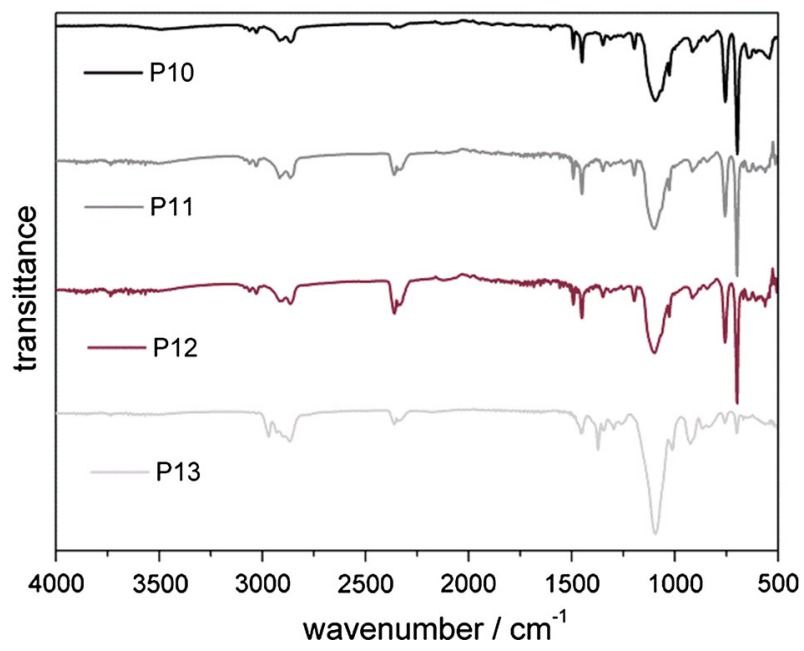

Fig. 8 FTIR ATR spectra for P10-P13: prepared with the use of K-DPG (I10 and I11) and 3KTKHMCH (I12 and I13)

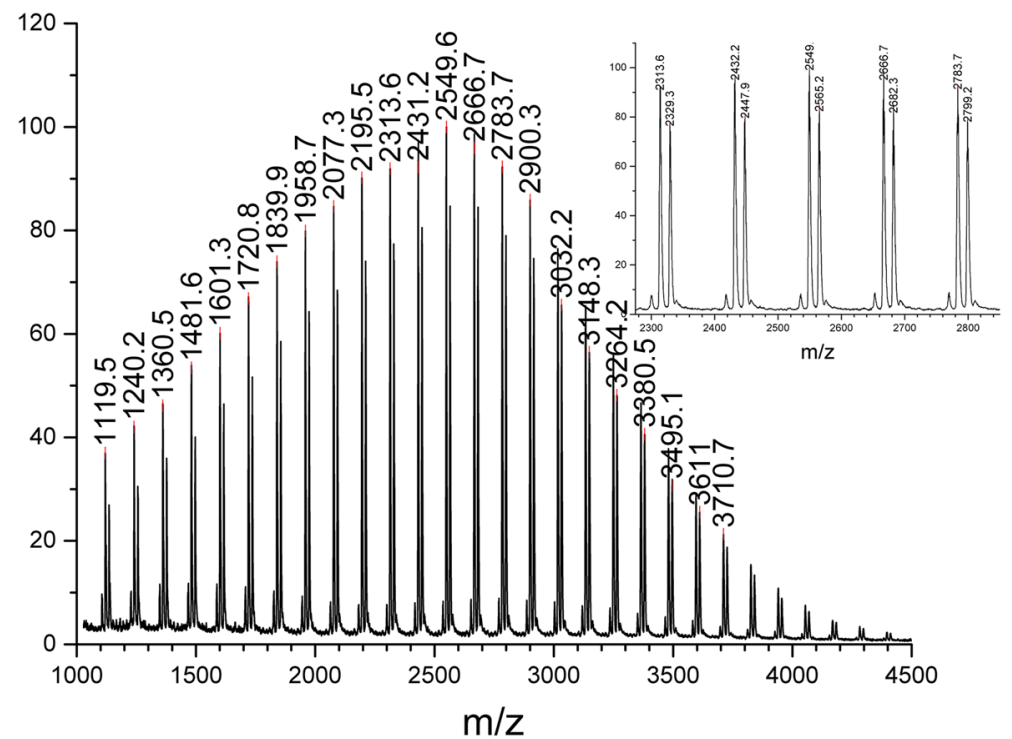

Fig. 9 MALDI-TOF spectrum of PSO-diol (P10) prepared with the use of K-DPG (I7) and quenched with $\mathrm{HCl} / \mathrm{H}_{2} \mathrm{O}$

of associated $-\mathrm{O}-\mathrm{H}$, while the peak at $1318 \mathrm{~cm}^{-1}$ is attributed to $\mathrm{O}-\mathrm{H}$ bending vibration. Complementary $\mathrm{C}-\mathrm{O}$ stretching band is visible in range $1260-1050 \mathrm{~cm}^{-1}$ with $1060 \mathrm{~cm}^{-1}$ stretching band of $\mathrm{C}-\mathrm{O}$ for primary alcohol. It is overlaid with ether $\mathrm{C}-\mathrm{O}-\mathrm{C}$ band located at $1095 \mathrm{~cm}^{-1}$ characteristic for alkyl-substituted ether.

MALDI-TOF analysis of polymer P10 further confirmed its chemical structure (Fig. 9). 


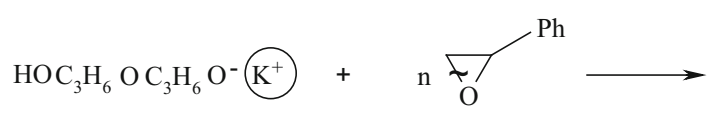

7
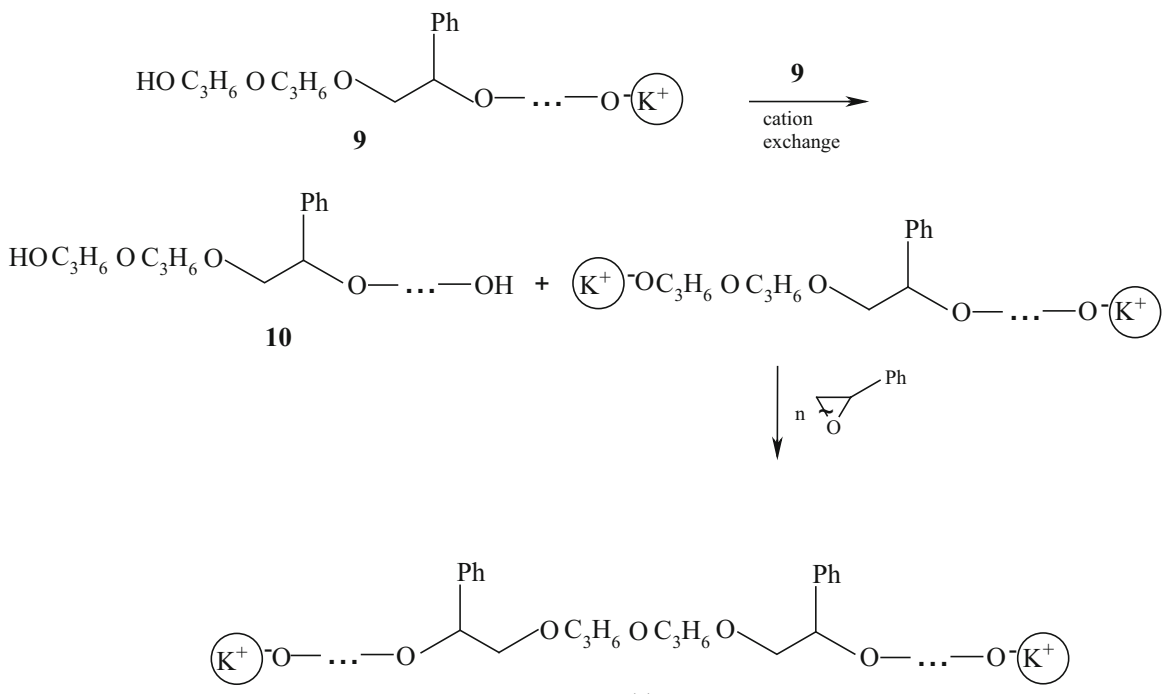

11<smiles>CCOC(COCCO)OCC(OCC)c1ccccc1</smiles>

Scheme 5 ROP of styrene oxide initiated with K-DPG

Two series of signals were observed in the spectrum. The first series at $\mathrm{m} / \mathrm{z}$ 1119.5-4055.3 represents macromolecules possessing central part $-\mathrm{OC}_{3} \mathrm{H}_{6} \mathrm{OC}_{3} \mathrm{H}_{6}$ $\mathrm{O}-$ derived from initiator and two $\mathrm{OH}$ terminal groups. For example, signals at $\mathrm{m} / \mathrm{z}$ 1360.4, 1840.6 and 2432.2 represent macromolecules containing 10, 14 and 19 mers of styrene oxide $\left(M_{n}\right.$ (calcd.) $=1358.7,1839.3$ and 2440.1$)$, respectively. They form as adducts with $\mathrm{Na}^{+}$ions. The second series at $m / z$ 1135.5-4071.3 represents macromolecules with the same structure, but forming adducts with $\mathrm{K}^{+}$ions. For example, signals at $\mathrm{m} / \mathrm{z} 1618.1,1974.1$ and 2447.9 belong to macromolecules with 12,15 and 19 mers of styrene oxide $\left(M_{n}\right.$ (calcd. $)=1614.5,1975.1$ and 2456.1).

Based on the results obtained we proposed the course of ROP for SO (Scheme 5).

Rapid cation exchange reaction between macromolecules $\mathbf{1 0}$ and $\mathbf{1 1}$ is responsible for activation of the former resulting consequently in the lack of starting $\mathrm{HOCH}\left(\mathrm{CH}_{3}\right) \mathrm{CH}_{2}-$ group. Deprotonation of hydroxyl groups present in polymer chains with alkoxide groups is very important reaction. It makes possible 

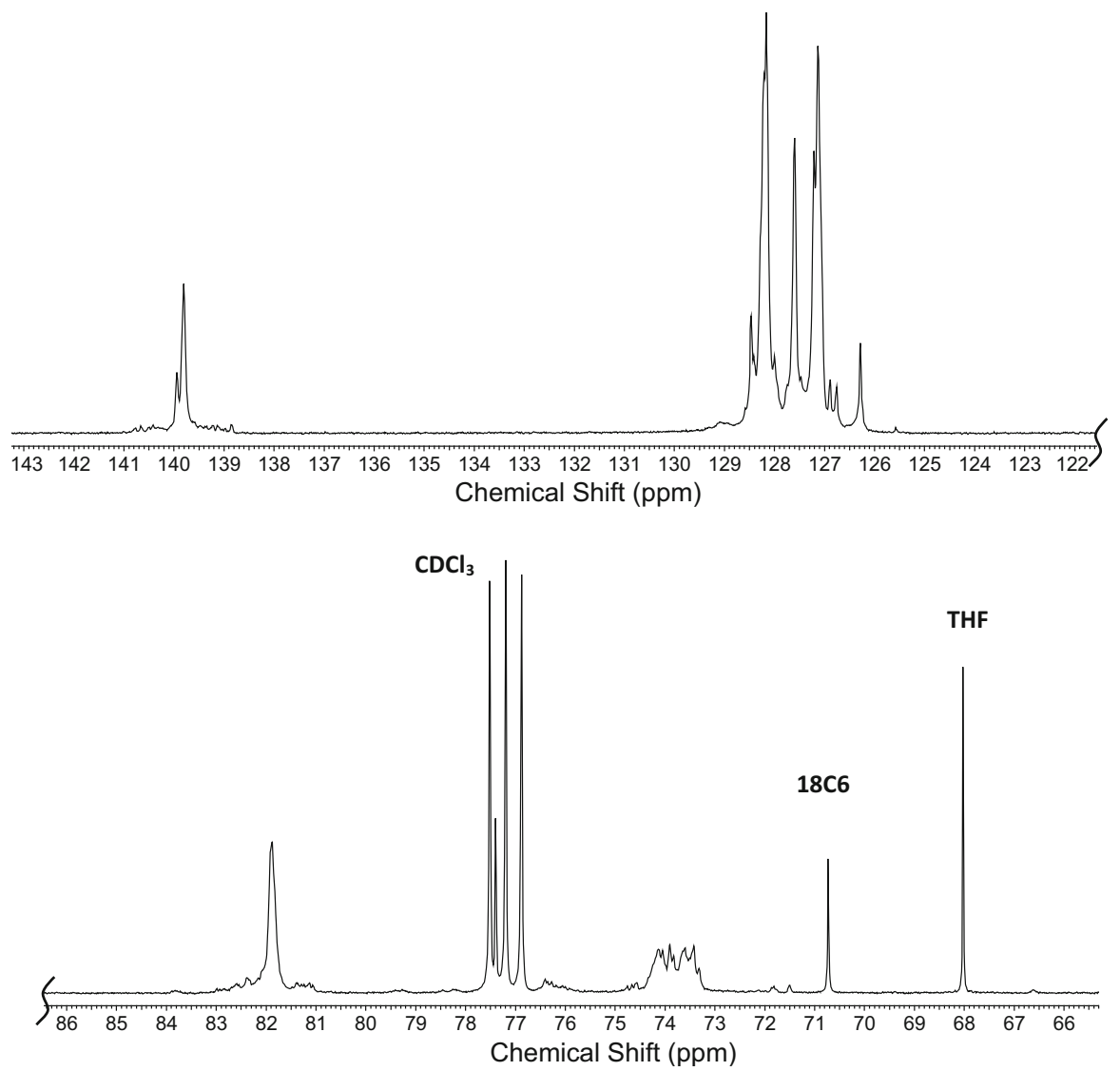

Fig. $10{ }^{13} \mathrm{C}$ NMR spectrum of PSO-pentol (P13) derived in ROP by use of 3K-THMCH (I8) and quenched with $\mathrm{HCl} / \mathrm{H}_{2} \mathrm{O}$

growth of chains in two directions and does not influence the concentration of active centers and polymer chains, i.e., does not influence $M_{n}$ of polymers. Moreover, this reaction strongly limits chain transfer reaction to the monomer and thus avoids decreasing of $M_{n}$.

In the last series of experiments tripotassium salt of TKHMCH (I8) was applied for SO polymerization. Figure 10 presents ${ }^{13} \mathrm{C}$ NMR spectrum of the polymer obtained at $[\mathrm{SO}]_{\mathrm{o}}=4.0 \mathrm{~mol} / \mathrm{dm}^{3}$.

In this spectrum the small signals at about 76.3 and $74.6 \mathrm{ppm}$ can be ascribed respectively to the first two $\mathrm{CH}_{2}$ carbons in the $-\mathrm{CH}_{2}-\mathrm{O}-\mathrm{CH}_{2}-\mathrm{CH}(\mathrm{Ph})-$ beginning part of the polymer chains connected to the initiator ring and indicating formation of the polymer, however, the carbon signals of the initiator ring itself are too weak to be observed. Nevertheless, MALDI-TOF analysis of the polymer confirmed its chemical structure (Fig. 11).

Two series of signals were shown in the spectrum. It was proposed that the first series of peaks at $\mathrm{m} / \mathrm{z}$, for example 897.8, 1137.5 and 1975.8 represents 


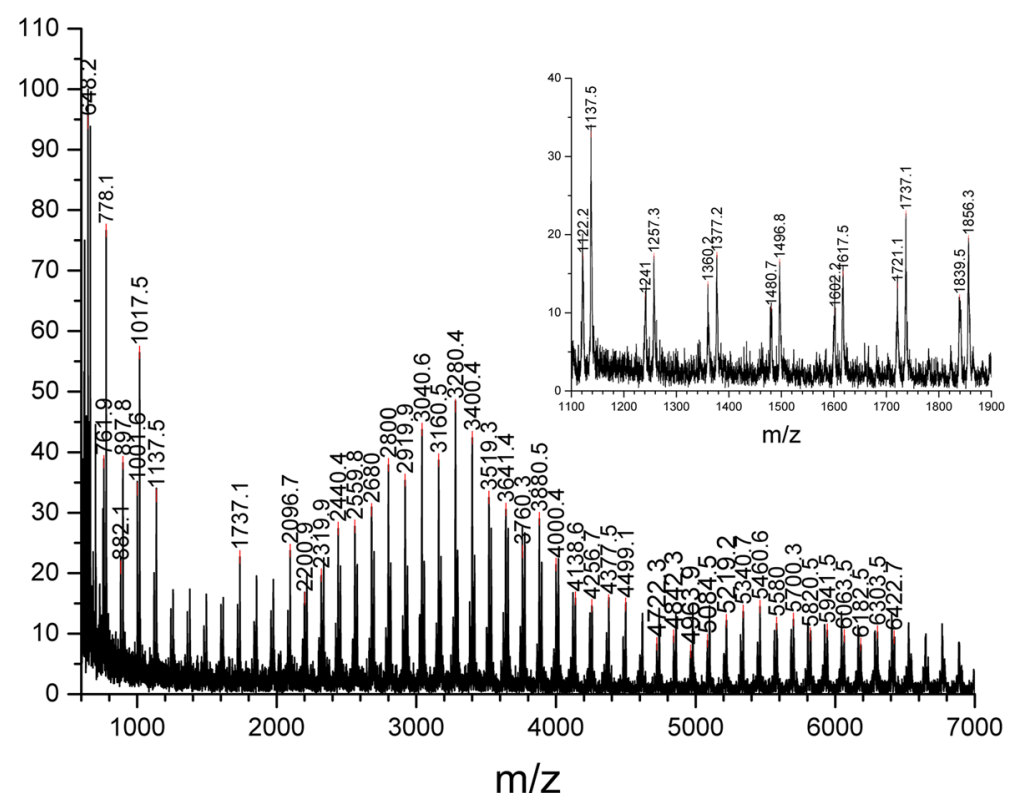

Fig. 11 MALDI-TOF spectrum of PSO-pentol (P13) synthesized with the use of 3K-THMCH (I8) and quenched with water

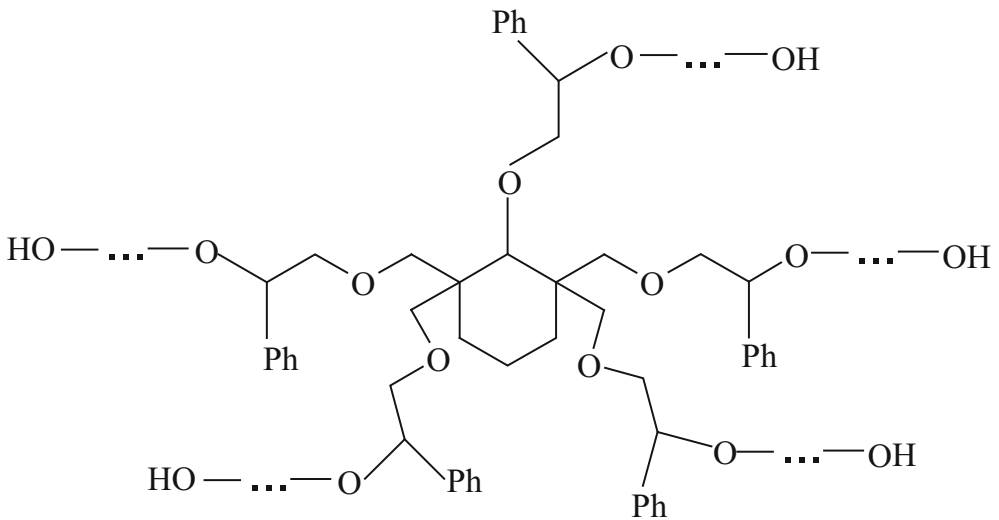

Scheme 6 Star-shaped macromolecules with five PSO-arms formed in SO ROP initiated with 3KTKHMCH (I8) and quenched with $\mathrm{HCl} / \mathrm{H}_{2} \mathrm{O}$

macromolecules having central part derived from initiator as well as four PSO arms with $\mathrm{OH}$ end groups and one arm with $\mathrm{OK}$ group. These macromolecules contain 5 , 7 and 14 mers of SO, respectively, and form adducts with $\mathrm{K}^{+}$ion $\left(M_{n}\right.$ (calcd.) $=898.2,1138.5$ and 1979.6, respectively). The second series of the signals at $m / z$ 1002.1, 1122.2 and 1960.4 represent macromolecules with the same structure which contain 6, 7 and 14 mers $\left(M_{n}\right.$ (calcd. $)=1001.3,1122.4$ and 1963.4, respectively) and form adducts with $\mathrm{Na}^{+}$ion. 
We proposed that the polymerization course is similar to that initiated with (I7), but in this case star-shaped macromolecules are formed (Scheme 6).

It is worth noting, that polymers obtained with salt (I8) consist of two or three fractions detected by the SEC method. This phenomenon can be explained by a strong tendency during polymerization to the formation of various macromolecular aggregates containing $\mathrm{OK}$ and $\mathrm{OH}$ groups with different reactivities [19].

\section{Conclusions}

Potassium alkoxides and hydroxyalkoxides activated by 18C6 are effective initiators of styrene oxide polymerization in THF solution at ambient temperature. The structure of polymers depends strongly on the kind of the initiators. The main characteristic features of the studied processes are:

- Initiation of SO polymerization with potassium methoxide occurs exclusively by oxirane ring opening in the $\beta$-position and not in the $\beta$ and $\alpha$ positions.

- Similar course of initiation was observed in the presence of potassium $t$ butoxide, 2-methylpropoxide and 1-phenylethoxide.

- Unexpectedly, potassium $i$-propoxide or 1-methylpropoxide opens the oxirane ring in the $\beta$ or $\alpha$ position.

- The polymers obtained indicate unsaturation resulting exclusively from deprotonation of monomer methine groups with active center of growing chain and initiator.

- Molar masses of polymers $\left(M_{n}=1700-4800 \mathrm{Da}\right)$ are much higher than reported in literature.

- Using monopotassium salt of dipropylene glycol and tripotassium salt of 2,2,6,6tetrakis(hydroxymethyl)cyclohexanol it was possible to synthesize PSO-polyols without unsaturation, which could be useful for preparation of new polyurethanes.

\section{Compliance with ethical standards}

Conflict of interest The authors declare that they have no conflict of interest.

Open Access This article is distributed under the terms of the Creative Commons Attribution 4.0 International License (http://creativecommons.org/licenses/by/4.0/), which permits unrestricted use, distribution, and reproduction in any medium, provided you give appropriate credit to the original author(s) and the source, provide a link to the Creative Commons license, and indicate if changes were made.

\section{References}

1. Reeve W, Christoffell J (1950) The reaction of styrene oxide with methanol. J Am Chem Soc 72:1480-1483. doi:10.1021/ja01160a014

2. Spirin YuL, Doroshenko NP (1972) Study of the anionic polymerization of styrene oxide. Vysokomol Soedin Ser A 14:646-652 
3. Kazanskii C, Reix M, Spassky N (1979) Effect of the chiral polymer chain in the anionic polymerization of styrene oxide. Polym Bull 1:793-799. doi:10.1007/BF00256281

4. Jedliński Z, Kasperczyk J, Dworak A, Matuszewska B (1982) The anionic polymerization of styrene oxide. Polymer structure and direction of ring opening. Macromol Chem 183:587-591. doi:10.1002/ macp. 1982.021830308

5. Stolarzewicz A, Neugebauer D (1999) Influence of substituent on the polymerization of oxiranes by potassium hydride. Macromol Chem Phys 200:2467-2470. doi:10.1002/(SICI)15213935(19991101)200:11<2467:AID-MACP2467>3.0.CO;2-3

6. Morejko B, Stolarzewicz A, Grobelny Z, Piekarnik B, Niedziela T, Trzebicka B (2007) New kind of star-shaped polyethers prepared with cyclic oligo(potassium glycidoxide) as macroinitiator. React Funct Polym 67:669-674. doi:10.1016/j.reactfunctpolym.2007.04.006

7. Izatt RM, Bradshaw JS, Nielsen SA, Lamb JD, Christensen JI (1985) Thermodynamic and kinetic data for cation-macrocycle interaction. Chem Rev 85:271-339. doi:10.1021/cr00068a003

8. Grobelny Z, Swinarew A, Jurek-Suliga J, Skrzeczyna K, Gabor J, Łężniak M (2016) The influence of crown ether and alcohol on unsaturation and molar mass of poly(propylene oxide)s prepared by use of potassium $t$-butoxide: reinvestigation of chain transfer reactions. J Anal Chem. doi:10.1155/2016/ 3727062

9. Koinuma H, Naito K, Hirai H (1982) Anionic polymerization of oxiranes. Macromol Chem 183:1383-1390

10. Kayan A (2015) Synthesis of poly(styrene oxide) with different molecular weights using tin catalysts. Des Monomers Polym 18(6):545-549. doi:10.1080/15685551.2015.1041086

11. Ge L, Huang Q, Zhang Y, Shen Z (2000) Ring-opening polymerization of styrene oxide with rare earth coordination catalysts. Eur Polym J 36(12):2699-2705. doi:10.1016/S0014-3057(00)00056-2

12. Hachemaoui A, Yahiaoui A, Belbachir M (2008) Structural and photooxidation studies of poly(styrene oxide) prepared with Maghnite- $\mathrm{H}^{+}$as cationic catalyst. Appl Polym Sci 110(5):3195-3202. doi:10.1002/app.28912

13. Oliveira SA, Moura CL, Cavalcante IM, Lopes AA, Leal L, Gramosa NV, Ribeiro M, Fraņa F, Yeates S, Ricardo N (2015) Binary Micellar Solutions of Poly(Ethylene Oxide)-Poly(Styrene Oxide) Copolymers with Pluronic ${ }^{\circledR}$ P123: Drug Solubilisation and Cytotoxicity Studies. J Braz Chem Soc. doi:10.5935/0103-5053.20150205

14. Cabón A, Rey-Rico A, Barbosa A (2013) Poly(styrene oxide)-poly(ethylene oxide) block copolymers: from "classical" chemotherapeutic nanocarriers to active cell-response inducers. J Controlled Release 167:68-75. doi:10.1016/j.jconrel.2013.01.010

15. Cambón A, Rey-Rico A, Barbosa S, Brea J, Loza MI, Yeates SG, Alvarez-Lorenzo C, Concheiro A, Taboada P, Mosquera V (2012) Polyethylene Oxide-Polystyrene Oxide Triblock Copolymers as Biological-Responsive Nanocarriers. MRS Proc 1468:12. doi:10.1557/opl.2012.1447

16. Harrold ND, Li Y, Chrisholm MH (2013) Studies of ring-opening reactions of styrene oxide by chromium tetraphenylporphyrin initiators. Mechanistic and stereochemical considerations. Macromolecules 46:692-698. doi:10.1021/ma302492p

17. Brown CA (1974) Potassium hydride, highly active new hydride reagent. Reactivity, applications, and techniques in organic and organometallic reactions. J Org Chem 39:3913-3918. doi:10.1021/ jo00940a025

18. Grobelny Z, Matlengiewicz M, Jurek J, Michalak M, Kwapulińska D, Swinarew A, Schab-Balcerzak E (2013) The influence of macrocyclic ligands and water on propylene oxide polymerization initiated with anhydrous potassium hydroxide in tetrahydrofuran. Eur Polym J 49:3277-3288. doi:10.1016/j. eurpolymj.2013.06.035

19. Penczek S, Cypryk M, Duda A, Kubisa P, Słomkowski S (2007) Living ring-opening polymerizations of heterocyclic monomers. Prog Polym Sci 32:247-282. doi:10.1016/j.progpolymsci.2007.01.002 